Article

\title{
Development of a Low-Cost, Wireless Smart Thermostat for Isothermal DNA Amplification in Lab-On-A-Chip Devices
}

\author{
Tamas Pardy *(D), Henri Sink, Ants Koel ${ }^{\mathbb{D}}$ and Toomas Rang \\ Thomas Johann Seebeck Department of Electronics, Tallinn University of Technology, 19086 Tallinn, Estonia \\ * Correspondence: tamas.pardy@taltech.ee
}

Received: 27 May 2019; Accepted: 27 June 2019; Published: 30 June 2019

\begin{abstract}
Nucleic acid amplification tests (NAAT) are widely used for the detection of living organisms, recently applied in Lab-on-a-Chip (LoC) devices to make portable DNA analysis platforms. While portable LoC-NAAT can provide definitive test results on the spot, it requires specialized temperature control equipment. This work focuses on delivering a generalized low-cost, wireless smart thermostat for isothermal NAAT protocols in $2 \mathrm{~cm} \times 3 \mathrm{~cm}$ LoC cartridges. We report on the design, prototyping, and evaluation results of our smart thermostat. The thermostat was evaluated by experimental and simulated thermal analysis using 3D printed LoC cartridges, in order to verify its applicability to various isothermal NAAT protocols. Furthermore, it was tested at the boundaries of its operating ambient temperature range as well as its battery life was evaluated. The prototype thermostat was proven functional in $20-30^{\circ} \mathrm{C}$ ambient range, capable of maintaining the required reaction temperature of 12 isothermal NAAT protocols with $0.7^{\circ} \mathrm{C}$ steady-state error in the worst case.
\end{abstract}

Keywords: Lab-on-a-Chip (LoC); finite element modelling; resistive heating; Point-of-Care (PoC); temperature control; computer-aided design; microfluidics; isothermal nucleic acid amplification tests; noninstrumented nucleic acid amplification tests (NINAAT); nucleic acid amplification tests (NAAT)

\section{Introduction}

Nucleic acid amplification test (NAAT) protocols are currently the gold standard in detecting living organisms on a cellular level, PCR (polymerase chain reaction) being the most widely used protocol [1,2]. A significant amount of effort goes into transferring NAATs into portable devices, in particular Lab-on-a-Chip (LoC) devices, for analytical or diagnostic field applications [3-6]. Isothermal NAAT protocols are particularly suitable for this format as, unlike PCR, they only require a single temperature target range to be maintained; therefore, they are easier to implement on compact, low cost hardware [7-10]. To facilitate the large-scale application of portable isothermal DNA amplification LoC devices, compact, low-cost, user-friendly electronics are needed, such as portable micropumps and heaters with built-in thermostats.

Heating elements used in LoC are typically electrical, with two main categories: external Peltier [11-14] and integrated resistive [15-17] or micro-Peltier [18-20]. All of these are regulated by thermostats that are typically external to the LoC device. Self-regulating resistive heating elements are an interesting novel solution to integrated temperature control as they require no thermostat [21-25]. However, due to the open-loop nature of the PTCR (positive temperature coefficient of resistance) effect used for control, they require extensive optimization to the particular NAAT protocol and ambient temperature conditions they are used in [21]. Noncontact electrical heating solutions include induction and microwave heating [26], but are impractical for portable applications. Lastly, nonelectrical solutions 
exist as well. Exothermic chemical reactions regulated by engineered phase-change materials offer extremely cheap ( 1 EUR) integrated heating [27-30], but their temperature control is challenging and they all require extensive optimization to their targeted operating conditions. In summary, general applicability to isothermal NAAT is only possible with the closed-loop control (typically using the well-known proportional-integral-derivative, aka. PID algorithm) that a thermostat can provide, and preferably using a resistive heating element.

Reported state of the art LoC NAAT applications typically focus on the PCR protocol and use external/integrated thermal cyclers [31-34]. For isothermal NAAT, it is possible to use a laboratory hot plate [35], a thermostat built for microfluidic chips [36] or even thermal cyclers programmed to hold at a specific temperature [37]. All methods employ closed-loop control and electrical heating (Peltier elements or resistive heating). Portable thermal regulators/cyclers for LoC NAAT fall into three categories regarding cost and product maturity: (1) prototypes for 100-500€ [38-41], (2) early market entries by start-up companies for 500-2500€ [42,43], and (3) mature commercial products from established brands for over $2500 €[26,36,44]$. Table 1 shows a comparison of temperature control solutions in the literature with respect to features and cost.

Table 1. Comparison of temperature control solutions for Lab-on-a-Chip (LoC) nucleic acid amplification tests (NAAT) devices reported in the literature.

\begin{tabular}{ccccccc}
\hline Solution & $\begin{array}{c}\text { Heating } \\
\text { Element }\end{array}$ & Control & $\begin{array}{c}\text { LoC } \\
\text { Interface \& } \\
\text { Insulation }\end{array}$ & $\begin{array}{c}\text { Any } \\
\text { Isothermal } \\
\text { NAAT? }\end{array}$ & $\begin{array}{c}\text { End-User Cost } \\
\text { (Estimated) (6) }\end{array}$ & Source \\
\hline Hot plate & Resistive & PID & No & Yes & $>500$ & {$[35,45]$} \\
\hline $\begin{array}{c}\text { External } \\
\text { products } \\
\text { only) }\end{array}$ & $\begin{array}{c}\text { Peltier/ } \\
\text { resistive }\end{array}$ & PID & $\begin{array}{c}\text { Examples } \\
\text { exist }\end{array}$ & Yes & $\begin{array}{c}\text { Peltier }>2500 \\
\text { Resistive }>500\end{array}$ & {$[26,36,44]$} \\
\hline $\begin{array}{c}\text { Integrated } \\
\text { Resistive/ } \\
\mu \text { Peltier }\end{array}$ & $\begin{array}{c}\text { PID or PTCR } \\
\text { effect }\end{array}$ & $\begin{array}{c}\text { Integrated to } \\
\text { LoC }\end{array}$ & No & $>500$ & {$[20-23,41]$} \\
\hline $\begin{array}{c}\text { Chemical } \\
\text { heating }\end{array}$ & $\begin{array}{c}\text { Exothermic } \\
\text { reaction }\end{array}$ & PCM & No & No & $<10$ & {$[27-30]$} \\
\hline This work & Resistive & PID & Yes & Yes & 100 & - \\
\hline
\end{tabular}

In previous works, we demonstrated the integration of commercially available electrical heating elements into isothermal LoC NAAT devices [46-50]. Furthermore, we demonstrated the application of a self-regulating PTCR polymer-resin heating element in a LoC NAAT device, including thermal analysis [21,51] and proof-of-concept LAMP tests [22]. Previously we focused exclusively on low-cost, integrated heating solutions for use specifically in single-use LoC devices and primarily on the LAMP assay. As the first step in developing a low-cost LoC platform for a wide variety of isothermal DNA amplification protocols, in this work, we introduce a novel low-cost, wireless smart thermostat. The device is battery-powered and offers remote control via Bluetooth. Contrary to our previous works, this work demonstrates an external thermostat applicable to LoC cartridges of specific dimensions, irrespective of microchannel geometry. The focus is on finding the best balance between low cost, user-friendliness, and performance. This paper reports on the thermostat design, as well as its validation with experimental and simulated thermal analysis at temperature targets required by a wide array of isothermal DNA amplification assays. Experimental thermal analysis is performed on 3D printed microfluidic cartridges with the standard $0.05 \mathrm{~mL}$ amplification volume, both by thermistor probes embedded in the channel and infrared thermometry to observe spatial distribution of heat. Simulation via finite element modelling is used to verify that the reaction volume is in range in steady state at each temperature target, as well as to define the best steady-state error achievable by the system. The thermal evaluation methodology used in this paper was demonstrated in our previous works [21,52]. 


\section{Materials and Methods}

\subsection{Thermostat Prototype Design}

The thermostat prototype (Figure 1) consisted of the electronics assembly, heater, microfluidic chip, battery, and the enclosure. The electronics assembly was constructed from a set of stacked circuit boards: an electronics interface board, a microcontroller board, and a user interface board. The enclosure included user input/output interfaces. Key design aspects were simplicity (cheap fabrication and materials), scalability, and user-friendliness. In this section, we discuss the electronics assembly (including the battery and user interfaces) and the enclosure. The heater is detailed in Section 2.2.

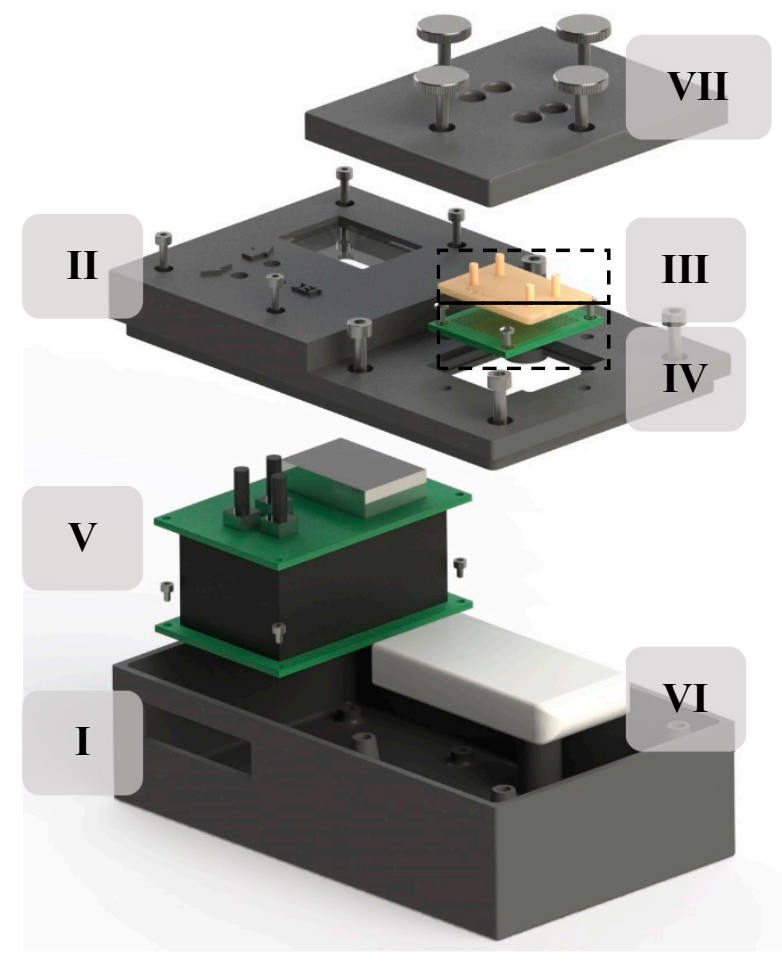

(a)

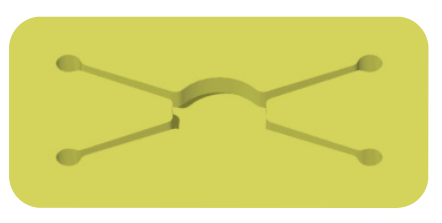

(b)

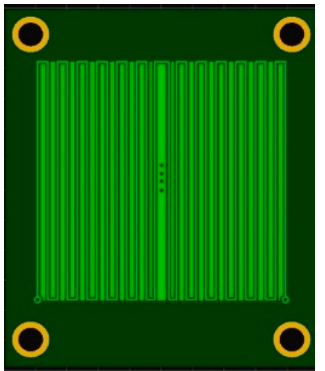

(c)

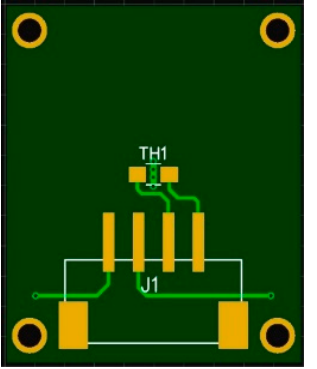

(d)

Figure 1. Rendering of the thermostat prototype showing system components (a). The prototype was $12 \mathrm{~cm} \times 8 \mathrm{~cm} \times 5 \mathrm{~cm}$ and consisted of the following components: Enclosure (I) with user interfaces (II), $2 \mathrm{~cm} \times 3 \mathrm{~cm}$ microfluidic chip holding $0.05 \mathrm{~mL}$ liquid volume (III), heater (IV), electronics assembly (V), Li-Po battery (VI), and the plastic cover (VII) for clamping down the chip and thermal insulation. The microfluidic reaction chamber $(\mathbf{b})$ and the heater $(\mathbf{c}, \mathbf{d})$ are shown separately in magnified view. For easier integration and minimal cost, the heater was implemented on a $2 \mathrm{~cm} \times 3 \mathrm{~cm}$ printed circuit board (PCB) board (c) with an SMD thermistor on the backside (d) for temperature regulation.

The core component of the electronics assembly was the microcontroller board based on the ESP32 SoC (System-on-Chip) [53]. We used the TTGO MINI 32 V2.0 development board (WeMos 
Inc., Guangdong, China), which was chosen due to its low cost, small footprint, integrated battery management, integrated Bluetooth 4.2/BLE (Bluetooth Low Energy) communication capabilities, and Arduino compatibility. The SoC board was connected to the electronics interface board, which was connected to the user interface board, the battery and the heater. The input current of the heater was regulated through an IRLZ44N (Infineon Technologies AG, Neubiberg, Germany) nMOSFET (metal-oxide-semiconductor field-effect transistor), controlled in turn by a GPIO (general purpose input-output) pin of the ESP32 using PWM (pulse width modulation). Additionally, the interface board had a TI ADS1115 (Texas Instruments, Dallas, Texas, USA) 16-bit low-power ADC (analog to digital converter) for temperature measurement (from the thermistor on the heater board), heater input current and battery voltage output measurement. The battery was a $3.7 \mathrm{~V}, 1200 \mathrm{mAh}$ Lithium-Ion battery. The device was designed to have two user input/output interfaces: a built-in OLED (organic light-emitting diode) display with three pushbuttons on the user interface board, and a Bluetooth serial interface for wireless control. The OLED display was controlled via the I2C interface of the ESP32. Two of the pushbuttons navigated up/down in the user menu and a third selected menu items. The Bluetooth serial interface was implemented using the BluetoothSerial Arduino library for the ESP32 by Espressif [54], which could offer up to $10 \mathrm{~m}$ communication range in an office environment [55]. A smartphone Bluetooth client was created in MIT App Inventor 2 for Android for configuring the thermostat remotely [56].

The enclosure was 3D printed by an FDM (fused deposition modelling) 3D printer (Ultimaker 2+, Ultimaker B.V., Geldermalsen, Netherlands) from ABS (acrylonitrile butadiene styrene) plastic. The prototype enclosure was $12 \mathrm{~cm} \times 8 \mathrm{~cm} \times 5 \mathrm{~cm}$ in total. One side of the enclosure was for user input-output, the other for the microfluidic chip interface. On the chip interface side, the heater was fastened to a slot perpendicular to the slot for the microfluidic chip. The chip was clamped down by a thick plastic cover that also acted as thermal insulation. The plastic cover had holes for the silicone tubing connected to the microfluidic chip. On the user interface side, above the electronics assembly, the enclosure had holes for the pushbuttons and a slot for the OLED display. The vertical wall next to the user interface had a slot for connecting cables to the electronics inside.

\subsection{Heating Element, Regulation, and Thermal Interface}

In this work, the decision was made to use printed circuit boards (PCBs) for heating due to their low cost $(\sim 0.03 € / \mathrm{pc})$, easy integration, and low thermal conductivity $(0.3 \mathrm{~W} /(\mathrm{m} \cdot \mathrm{K}))$. This solution is similar to etched foil or patterned thin film resistive heaters, but instead of commonly used resistive materials, copper tracks are used for heating. Due to the low resistivity of copper, this results in a low-power resistive heater. Furthermore, even the cheapest PCBs have excellent height uniformity, eliminating the need for additional heat spreaders or thermal compounds on the thermal interface. The prototype we designed had a copper heating track ( $~ 0.036 \mathrm{~mm}$ layer thickness, $4 \mathrm{~cm}^{2}$ area) and copper fills in between to spread heat evenly, covered by solder mask for electrical insulation. In the middle of the heater there was a copper fill and vias to the backside where the thermistor was located (position TH1 in Figure 1). This was to ensure good heat transfer to the thermistor. A 10K NTC thermistor (NCP21XV103J03RA, Murata Manufacturing Co., Ltd., Nagaokakyo, Kyoto, Japan) was used for providing temperature feedback for controlling the output of the heater. The heater and the thermistor were connected by a four-pin header (J1 in Figure 1). Prototypes were ordered from JLCPCB (Shenzhen JIALICHUANG Electronic Technology Development Co., Ltd., Shenzhen, China).

The heater's current input was regulated by an nMOSFET, in turn controlled from one of the GPIO interfaces of the ESP32 (see Section 2.1). Heater power control was realized by PWM (pulse-width modulation) control of the FET's output. The control algorithm was based on a PID (proportional-integral-derivative) loop running on the ESP32 SOC. Due to rapid temperature changes, the derivative term can vary significantly between each iteration. To avoid this, the differential term was the moving average of five iterations. This was easy to calculate and reduced oscillations. The integral term was calculated as the sum of the previous iteration's integral term and the error, 
multiplied by the time interval between the iterations. PID constants were tuned by the well-known Ziegler-Nichols method. The feedback for PID control was the heater surface temperature, monitored by the thermistor on the heater board. The output of the thermistor was converted by the well-known Steinhart-Hart equation.

The thermal interface between the heater and heated liquid consisted of two layers, i.e., a $\sim 0.15 \mathrm{~mm}$ thick plastic foil laminating the fluidic chip (Greiner MTP sealers, Greiner Holding AG, Austria) and the $\sim 0.02 \mathrm{~mm}$ thick solder mask, both negligible compared to the heater area $\left(4 \mathrm{~cm}^{2}\right)$ and the microreactor area ( $40 \mathrm{~mm}^{2}$, including inlet channels). To ensure quick and easy replacement of microfluidic chips, no thermal interface material was used. The heater and the heated microfluidic chip are insulated by the plastic enclosure (this is sufficient due to the microreactor being only $\sim 10 \%$ of the total heated area and far smaller than the surrounding enclosure).

\subsection{Thermal Modelling}

The thermal model detailed in this work was designed for stationary thermal analysis and a 3D device geometry with well-defined structural materials and boundary conditions. The model was a simplified 3D representation of the experimental setup. The heater was represented as a temperature boundary condition, given that the steady-state heater surface temperature was known and experimentally verified for each set point. Therefore, the model was based on the heat transfer equation assuming no flow (during amplification, the reaction liquid is stationary). Thermal properties (density, heat conductivity, specific heat capacity) of the structural materials in the model are detailed in Table 2. Boundary conditions and initial values are detailed in Table 3. Ambient temperature for the model was set to a constant $25^{\circ} \mathrm{C}$.

Table 2. Summary of material properties used in the model.

\begin{tabular}{cccc}
\hline Material & Density $\left(\mathbf{k g} / \mathbf{m}^{\mathbf{3}}\right)$ & Thermal Conductivity $(\mathbf{W} / \mathbf{m K})$ & Specific Heat Capacity $\mathbf{( J /} \mathbf{k g} \cdot \mathbf{K}))$ \\
\hline 3D printed plastic & 1470 & 0.18 & 1190 \\
Copper & 8960 & 400 & 385 \\
FR4 & 1900 & 0.143 & 1369 \\
Air & 1225 & 0.024 & 1000 \\
Water & 1000 & 0.6 & 4184 \\
\hline
\end{tabular}

Table 3. Summary of boundary conditions and initial parameter values used in the model.

\begin{tabular}{ccc}
\hline Boundary Condition & Boundary & Initial Value (If Applicable) \\
\hline Ambient temperature & External boundaries & $25^{\circ} \mathrm{C}$ \\
Ambient pressure (absolute) & External boundaries & $1 \mathrm{~atm}$ \\
Heater & Heater track surface & As per set point \\
Convective heat loss & External boundaries & Not applicable \\
Electrical insulation & Heater boundaries except contacts & Not applicable \\
Radiative heat loss & External boundaries & Not applicable \\
\hline
\end{tabular}

The model was implemented in COMSOL ${ }^{\circledR}$ Multiphysics version 5.4 using the Heat Transfer interface. The model was solved via the built-in stationary solver of COMSOL on a PC with a Core i7-7700 CPU with 32 GB RAM. The 3D model of the device was imported from Autodesk Inventor and defeatured to decrease mesh complexity: screws and fillets were removed, and the battery and the circuitry were replaced with blocks of the same size. Convective, conductive, and radiative heat losses were taken into account in the model. The model had 36 distinct domains and 1223 boundaries, all of which were included in the calculation. The thermistor in the microreactor was modelled as a Domain Point Probe at the same height as in the experimental model. A tetrahedral mesh was generated in COMSOL using the built-in Finer settings, resulting in 1,301,982 elements of an average element quality (based on the well-known radius ratio method [57]) of 0.63 and element size of $0.3 \mathrm{~mm}^{3}$. 


\subsection{Experimental Setup for Thermal Characterization}

The experimental setup consisted of the thermostat prototype and a microfluidic chip. The microfluidic chip $(3 \mathrm{~cm} \times 2 \mathrm{~cm} \times 1.5 \mathrm{~mm})$ had two inlet and two outlet features and was designed to hold $\sim 50 \mu \mathrm{L}$ liquid (standard DNA amplification volume [58]). Chip prototypes were 3D printed using a DLP (digital light processing) 3D printer (Envisiontec Perfactory 4, Envisiontec GmbH, Gladbeck, Germany), and the channels of the microfluidic chip were sealed with Greiner MTP sealers (Greiner Holding AG, Austria). For reaction temperature measurements, a bead-type thermistor $(\mathrm{P} / \mathrm{N}$ GA10K4A1A, TE Connectivity Ltd., Schaffhausen, Switzerland) was embedded in the channel through a hole drilled from above and sealed in with thermoplastic adhesive. The sensor was connected to an Agilent 34410A digital multimeter (Agilent Technologies Inc., Santa Clara, CA, USA) and recorded on a PC via a MATLAB ${ }^{\circledR}$ script. Before experiments, an empty and a water-filled $3 \mathrm{~mL}$ syringe were connected to the inlets, and open tubes to the outlets of the microfluidic chip. After filling the reaction chamber with distilled water, the tubes connected to the outlets were clamped shut by IV clamps. Experiment data (timestamped heater temperature, input current and voltage) was recorded by streaming data through the microcontroller's USB serial interface to PuTTY running on a PC.

\section{Results and Discussion}

\subsection{Initial Thermal Characterization}

Initial characterization was done in an air-conditioned office maintained at $25^{\circ} \mathrm{C}\left( \pm 2{ }^{\circ} \mathrm{C}\right)$ to ensure easy access to the experimental setup. Heater base resistance was measured using the aforementioned Agilent digital multimeter at $3 \Omega$. Next, thermal characterization was performed on the experimental setup. Three consecutive thermal transients were recorded for $15 \mathrm{~min}$, each time allowing the system to cool back to room temperature afterwards (Figure 2). The goal was to determine the time constant (in this context calculated as the time it took for reaction temperature to enter steady-state with $0.5^{\circ} \mathrm{C}$ tolerance) and verify that the steady-state error (SSE) of control was within $\pm 1^{\circ} \mathrm{C}$. For this measurement and the following ones, based on the required SSE, steady-state was defined as starting from being within $1{ }^{\circ} \mathrm{C}$ from the set point.

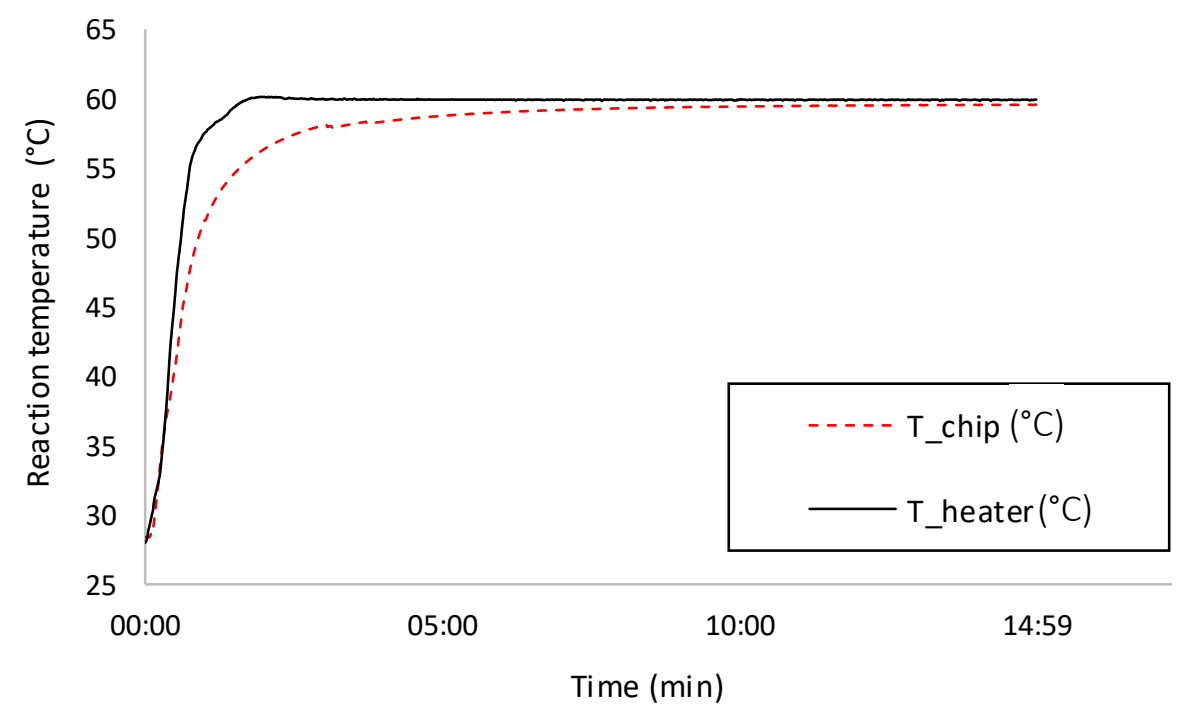

Figure 2. Initial thermal transient characterization of the experimental prototype. With a set point of $60{ }^{\circ} \mathrm{C}$, the time constant for the heater was $1 \mathrm{~min} 29 \mathrm{~s}$, for the microreactor it was $5 \mathrm{~min} 58 \mathrm{~s}$, the steady-state error was $0.35^{\circ} \mathrm{C}$. The initial temperature overshoot of the heater was due to integral windup and had no effect on reaction temperature control. 
With a set point of $60^{\circ} \mathrm{C}$, the time constant for the heater was $1 \mathrm{~min} 29 \mathrm{~s}( \pm 9 \mathrm{~s})$, for the microreactor it was $5 \mathrm{~min} 58 \mathrm{~s}( \pm 17 \mathrm{~s})$, the steady-state error was $0.35^{\circ} \mathrm{C}\left( \pm 0.06{ }^{\circ} \mathrm{C}\right)$, within the required range. The MCU (microcontroller unit) of the thermostat monitored the input current of the heater and the input voltage from the battery. Using these values, steady-state power was calculated as $0.75 \mathrm{~W}( \pm 0.005 \mathrm{~W})$.

\subsection{Validation of Thermal Simulation Model}

To verify the accuracy of the simulation model, infrared images of the experimental setup were recorded (using a Jenoptik VarioCAM 384 HiRes IR camera, Jenoptik AG, Jena, Germany) and compared to the model. Recordings were made at room temperature $\left(25^{\circ} \mathrm{C}\right.$ in an air-conditioned office $)$ and the thermostat was set to $60^{\circ} \mathrm{C}$. The model was solved using the Stationary Solver of COMSOL ${ }^{\circledR}$ Multiphysics version 5.4. For a single set of parameters, solution time was between 1-2 min. The same spot was compared on experimental and simulated thermal images (marked by black cross on Figure 3). On the simulated image, the temperature was $56.19^{\circ} \mathrm{C}$, whereas on the experimental image it was $56.04{ }^{\circ} \mathrm{C}$, indicating an estimation error of $0.15^{\circ} \mathrm{C}$ on the surface (Figure 3 ). Please note that the surface of the chip was exposed on these recordings, thus the lower surface temperature than the prescribed setpoint. Comparing the embedded temperature sensors in the microreactor, the absolute error between the simulated and experimental recording was $0.28^{\circ} \mathrm{C}$, within the required SSE range.

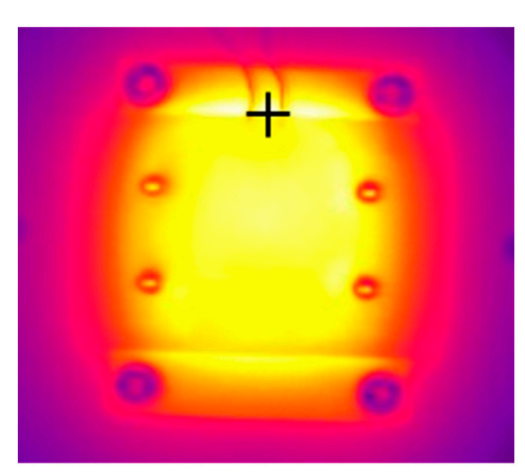

(a)

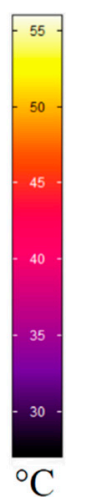

${ }^{\circ} \mathrm{C}$

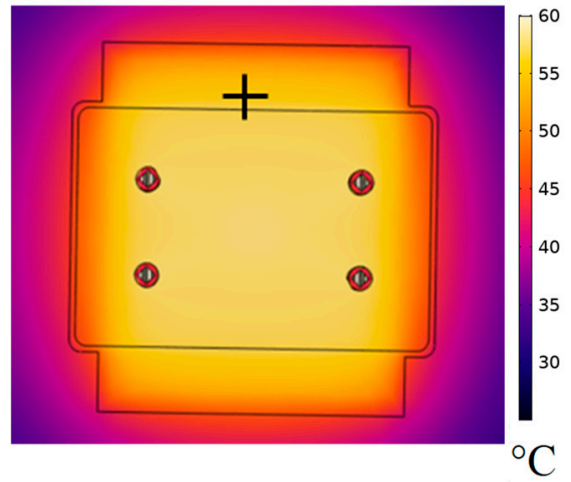

(b)

Figure 3. Steady-state surface temperature distribution on infrared image of experimental setup (a) and simulated thermal model (b). The thermal model was defeatured (screws, filleting etc. were removed) to decrease computational complexity for the model. Directly comparing temperatures in the same spot (marked by a black cross) on experimental and simulated thermal images indicated an absolute error of $\sim 0.2{ }^{\circ} \mathrm{C}$.

\subsection{Steady-State Thermal Analysis}

To assess the heating performance of the thermostat prototype, steady-state thermal analysis was conducted. Experiments were performed in a climate chamber (Vötsch VT 7004, Vötsch Industrietechnik $\mathrm{GmbH}$, Bailingen, Germany) incubated for $30 \mathrm{~min}$ before each test at $25^{\circ} \mathrm{C}$ to reach the correct ambient temperature and allow the prototype to cool down to ambient temperature. Each experiment involved recording a thermal transient for $15 \mathrm{~min}$ with the thermostat set to the defined set point. Tested set points were defined in the $35-65^{\circ} \mathrm{C}$ range with $5{ }^{\circ} \mathrm{C}$ steps, matching the requirements of 12 distinct isothermal amplification protocols as listed in Table 4 . The thermostat prototype was powered from its internal battery. This was achieved by cutting the power wire of the micro-USB connector used for data transfer from the thermostat. 
Table 4. Summary of experimental thermal analysis including time constants, power consumption and steady-state error for various nucleic acid amplification test (NAAT) protocols [31].

\begin{tabular}{cccccc}
\hline NAAT Protocol & $\begin{array}{c}\text { Target Range } \\
\left({ }^{\circ} \mathbf{C}\right)\end{array}$ & Set Point $\left({ }^{\circ} \mathbf{C}\right)$ & $\begin{array}{c}\text { Steady-State Error } \\
\left(\text { SSE) }\left({ }^{\circ} \mathbf{C}\right)\right.\end{array}$ & $\begin{array}{c}\text { Steady-State } \\
\text { Power }(\mathbf{W})\end{array}$ & Time Constant \\
\hline RAM & 35 & 35 & 0.48 & 0.18 & $2 \mathrm{~min} 39 \mathrm{~s}$ \\
RPA, BAD AMP & $37-42$ & 40 & 0.63 & 0.26 & $2 \mathrm{~min} 47 \mathrm{~s}$ \\
SPIA & $45-50$ & 45 & 0.17 & 0.37 & $5 \mathrm{~min} 41 \mathrm{~s}$ \\
EXPAR, NEAR & $45-50$ & 50 & 0.37 & 0.49 & $6 \mathrm{~min} 29 \mathrm{~s}$ \\
TMA, ICA, PG-RCA & $55-55$ & 55 & 0.08 & 0.59 & $6 \mathrm{~min} 56 \mathrm{~s}$ \\
LAMP, CPA, NEMA & 60 & 60 & 0.46 & 0.71 & $7 \mathrm{~min} 8 \mathrm{~s}$ \\
\hline
\end{tabular}

Table 4 summarizes the set points, corresponding steady-state errors, steady-state power consumption values of the heater and time constants related to the reaction temperatures in the microreactor. Power consumption was once again calculated from the input current and voltage drop measured by the thermostat. Each set point was tested twice, and values averaged. The highest time constant was $7 \mathrm{~min} 8 \mathrm{~s}$ for a set point of $65^{\circ} \mathrm{C}$; the lowest was $2 \mathrm{~min} 39 \mathrm{~s}$ for $35^{\circ} \mathrm{C}$. The maximum steady-state power consumption was $0.81 \mathrm{~W}$, the minimum was $0.18 \mathrm{~W}$ for the same temperatures. The highest SSE was $0.63^{\circ} \mathrm{C}$ for the set point of $40{ }^{\circ} \mathrm{C}$, still within the required boundaries. The lowest SSE of $0.08{ }^{\circ} \mathrm{C}$ was recorded at a set point of $55^{\circ} \mathrm{C}$. With applying offsets for the thermistor, the SSE could be reduced close to zero, but the demonstrated prototype was already within the required boundaries for every tested set point.

Simulated thermal analysis was performed as the next step. However, before the model was used for analysis, it was verified that the estimation error was within the desired SSE range. The model described in Section 2.3 was solved using the Stationary Solver of COMSOL. A Parametric Sweep was set up to include all seven set points. Solution time was $10 \mathrm{~min} 16 \mathrm{~s}$. Estimation error was calculated as the absolute error between experimentally recorded and simulated thermistor outputs in steady-state. The highest error was $0.53^{\circ} \mathrm{C}$, within the required range. The mean absolute error was $0.25^{\circ} \mathrm{C}\left( \pm 0.16^{\circ} \mathrm{C}\right)$. Table 5 summarizes steady-state temperatures recorded experimentally, compared to simulated values for all tested set points.

Table 5. Summary of simulated thermal analysis for various nucleic acid amplification test (NAAT) protocols [31].

\begin{tabular}{|c|c|c|c|c|c|}
\hline NAAT Protocol & $\begin{array}{c}\text { Target Range } \\
\left({ }^{\circ} \mathrm{C}\right)\end{array}$ & Set Point $\left({ }^{\circ} \mathrm{C}\right)$ & $\begin{array}{c}\text { Experimental } \\
\text { Steady-State }\left({ }^{\circ} \mathrm{C}\right)\end{array}$ & $\begin{array}{c}\text { Simulated } \\
\text { Steady-State }\left({ }^{\circ} \mathrm{C}\right)\end{array}$ & $\begin{array}{l}\text { Volume in } \\
\text { Range }(\mu \mathrm{L})\end{array}$ \\
\hline RAM & 35 & 35 & 34.52 & 34.94 & 48.62 \\
\hline RPA, BAD AMP & $37-42$ & 40 & 39.37 & 39.90 & 49.89 \\
\hline \multirow{2}{*}{ SPIA } & $45-50$ & 45 & 44.83 & 44.87 & 48.43 \\
\hline & $45-50$ & 50 & 49.63 & 49.83 & 47.72 \\
\hline EXPAR, NEAR & $55-55$ & 55 & 54.92 & 54.80 & 44.74 \\
\hline TMA, ICA, PG-RCA & 60 & 60 & 59.54 & 59.77 & 43.32 \\
\hline LAMP, CPA, NEMA & 65 & 65 & 64.54 & 64.73 & 43.408 \\
\hline
\end{tabular}

In a previous work, we established that $\sim 85 \%$ of the reaction liquid had to be in range for the amplification reaction to conclude successfully [22]. Based on this assumption, at least $42.5 \mu \mathrm{L}$ of the reaction liquid had to be in the correct range, defined as maximum $\pm 1{ }^{\circ} \mathrm{C}$ from the set point. From the simulated thermal model, the reaction liquid volume in range could be estimated. Based on a previous work of ours, we evaluated the volume in range using a logical condition defined in the COMSOL, evaluated for each finite element within the reaction chamber. This can be represented as the following formula:

$$
\eta=50 \cdot \frac{1}{n} \sum_{i=1}^{\mathrm{n}}\left(\left(\mathrm{T}_{\mathrm{i}}>(\mathrm{SP}-1)\left({ }^{\circ} \mathrm{C}\right) \cap \mathrm{T}_{\mathrm{i}}<(\mathrm{SP}+1)\left({ }^{\circ} \mathrm{C}\right)\right) \in\{0 ; 1\}\right)
$$


where SP denotes the set point, $T_{i}$ denotes temperature values for each finite element, $\mathrm{n}$ the total element number and $\eta \in[0 ; 50](\mu \mathrm{L})$.

Table 5 summarizes the estimated reaction volumes in range for each tested set point. The lowest value was $43.32 \mu \mathrm{L}$ at $60{ }^{\circ} \mathrm{C}$ set point, whereas the average was $46.59 \mu \mathrm{L}( \pm 2.5 \mu \mathrm{L})$, both above the required threshold.

To summarize, we performed steady-state thermal analysis, both experimental and simulated, on the thermostat prototype to verify functionality for various isothermal amplification protocols in $50 \mu \mathrm{L}$ amplification volume, at $25^{\circ} \mathrm{C}$ ambient temperature (Figure 4). The thermostat was tested with set points with $5{ }^{\circ} \mathrm{C}$ steps within the $35-65^{\circ} \mathrm{C}$ range, corresponding to 12 distinct amplification protocols. We concluded that with the tested parameters, the prototype was capable of regulating reaction temperatures in the desired target ranges with steady-state errors below $0.7^{\circ} \mathrm{C}$. Target temperatures were reached within less than $8 \mathrm{~min}$ and maintained with less than $1 \mathrm{~W}$ power consumption. Furthermore, we have demonstrated by simulation that $>85 \%$ of the reaction volume was in range for all tested set points. Therefore, our proposed device design was proven valid for use at $25^{\circ} \mathrm{C}$ ambient temperature, for all the listed isothermal amplification protocols.

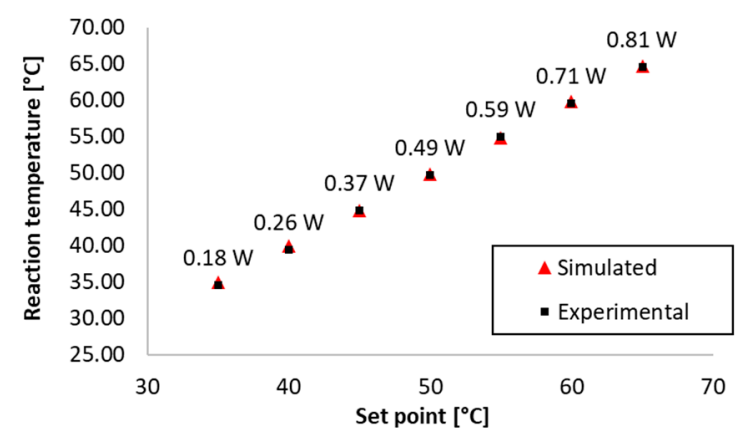

(a)

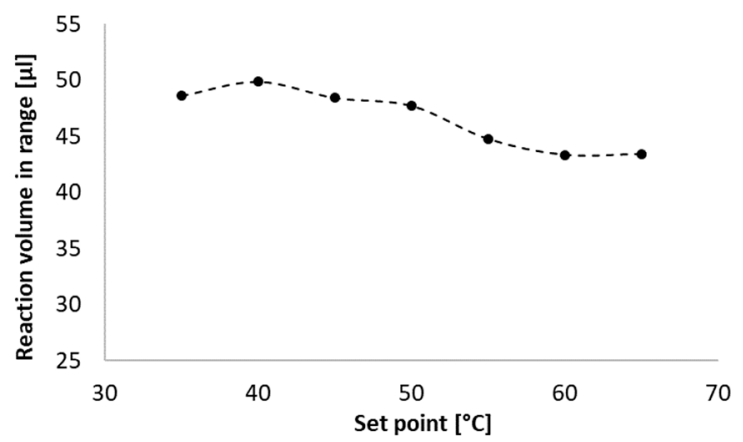

(b)

Figure 4. Experimental and simulated steady-state temperatures at various set points (a) as well as estimated reaction volume in range (b) corresponding to them. Power consumption is shown above temperature data points. Temperature data points were recorded in the $35-65^{\circ} \mathrm{C}$ range with $5{ }^{\circ} \mathrm{C}$ steps, at $25^{\circ} \mathrm{C}$ ambient temperature, corresponding to 12 isothermal amplification protocols performed in a regular office/laboratory environment. The prototype was demonstrated capable of performing these protocols with respect to reaching and maintaining target temperatures as well as holding above $85 \%$ of the reaction liquid in the required temperature range.

\subsection{Stress Test and Battery Life Estimation}

We subjected the thermostat to stress testing. The operating ambient temperature for the thermostat was defined as $20-30^{\circ} \mathrm{C}$, corresponding to the limits of comfortable room temperature. Therefore, we tested whether the prototype could maintain a higher set point at these extremes. As in Section 3.4, testing was performed in the climate chamber, but this time the thermostat was unplugged and running from the internal battery. Three tests were done at both $20^{\circ} \mathrm{C}$ and $30^{\circ} \mathrm{C}$ ambient temperature, each time recording a transient of $15 \mathrm{~min}$. At $20^{\circ} \mathrm{C}$ ambient temperature, the average steady-state reaction temperature was $64.29^{\circ} \mathrm{C}\left( \pm 0.07^{\circ} \mathrm{C}\right)$, heater temperature was $65^{\circ} \mathrm{C}\left( \pm 0.001^{\circ} \mathrm{C}\right)$, with $0.89 \mathrm{~W}( \pm 0.06 \mathrm{~W})$ power consumption and SSE of $0.71{ }^{\circ} \mathrm{C}\left( \pm 0.07^{\circ} \mathrm{C}\right)$. The time constant was $8 \mathrm{~min} 43 \mathrm{~s}( \pm 32 \mathrm{~s})$. At $30{ }^{\circ} \mathrm{C}$ ambient temperature, the average steady-state reaction temperature was $64.31{ }^{\circ} \mathrm{C}\left( \pm 0.11^{\circ} \mathrm{C}\right)$, heater temperature was $64.99^{\circ} \mathrm{C}\left( \pm 0.001^{\circ} \mathrm{C}\right)$, with $0.77 \mathrm{~W}( \pm 0.09 \mathrm{~W})$ power consumption and SSE of $0.69{ }^{\circ} \mathrm{C}\left( \pm 0.11^{\circ} \mathrm{C}\right)$. The time constant was $7 \mathrm{~min} 20 \mathrm{~s}( \pm 8 \mathrm{~s})$. Thus, it was demonstrated that the thermostat was capable of operating within the requirements at the extreme ends of the operating ambient temperature range.

Finally, we estimated the battery life by running the thermostat at the lower end of the operating ambient range, $20^{\circ} \mathrm{C}$, at the highest allowed set point, $70^{\circ} \mathrm{C}$. Lifetime was calculated from start until 
the reaction temperature was within $\pm 1{ }^{\circ} \mathrm{C}$ of the targeted set point. With a $1200 \mathrm{mAh}$ battery and the defined test conditions, regulation failed at $3 \mathrm{~h} 15 \mathrm{~min} 55 \mathrm{~s}$. That is, calculating with an average of 30 min per amplification assay, in the worst case, six isothermal amplifications can be completed with a single charge. This can be easily extended by changing the internal battery for a larger capacity option or connecting the thermostat to a cheap, widely available, portable external battery via micro-USB.

\section{Conclusions}

In this work, we demonstrated a low-cost, wireless smart thermostat for isothermal NAAT in $2 \mathrm{~cm} \times 3 \mathrm{~cm}$ LoC cartridges. The prototype thermostat was based on the ESP32 SoC and had Bluetooth connectivity, a $1200 \mathrm{mAh}$ battery, and a built-in OLED display and buttons for local status monitoring and configuration. The prototype heater was a custom PCB with copper tracks acting as the heating circuit, and its output was regulated by an nMOSFET via PWM, based on data from an onboard thermistor. An additional ADC was used to monitor electrical parameters within the system. The prototype enclosure and the LoC cartridge used for the tests were 3D printed.

The prototype was evaluated experimentally and via finite element modelling, to prove its functionality for various isothermal NAAT protocols. Initial thermal characterization was performed by recording $15-\mathrm{min}$ thermal transients at room temperature with a set point of $60{ }^{\circ} \mathrm{C}$. Meanwhile, the LoC cartridge was filled with water. In this initial test, the time constant was 1.5 min for the heater and $6 \mathrm{~min}$ for the microreactor, with an SSE of $0.35^{\circ} \mathrm{C}$. With the same experimental parameters, infrared thermometry was performed and compared to the finite element model for the prototype. The model was capable of estimating experimentally recorded temperatures with an absolute error of $0.28{ }^{\circ} \mathrm{C}$. As the next step, steady-state thermal analysis was performed both via experimental and simulated methods. Set points were defined in the $35-65^{\circ} \mathrm{C}$ range characteristic of isothermal NAAT protocols, with $5{ }^{\circ} \mathrm{C}$ steps. Each experiment was performed in a climate chamber maintained at $25^{\circ} \mathrm{C}$, and each set point was recorded twice with 15-min thermal transients. The maximum SSE was $0.63{ }^{\circ} \mathrm{C}$, steady-state power $0.81 \mathrm{~W}$ and time constant $7 \mathrm{~min}$. Simulated thermal analysis was used to determine how much of the reaction volume was in range. Previously, we established that at least $85 \%$ of the volume had to be in range. Of the $50 \mu \mathrm{L}$ reaction volume in our LoC prototype, at least $43.32 \mu \mathrm{L}$ was in range for all of the tested set points. The prototype was also tested at the boundaries of its operating ambient temperature range $\left(20-30^{\circ} \mathrm{C}\right)$, with $65^{\circ} \mathrm{C}$ set point, to test a worst case. At these parameters, maximum SSE was $0.71^{\circ} \mathrm{C}$, power consumption $0.89 \mathrm{~W}$, time constant $8 \mathrm{~min} 43 \mathrm{~s}$. The battery life of the prototype was tested at $20^{\circ} \mathrm{C}$ ambient with $70{ }^{\circ} \mathrm{C}$ set point, to evaluate the worst case. Lifetime was calculated as the time duration until which reaction temperature was regulated within $1^{\circ} \mathrm{C}$ of the set point. This resulted in a lifetime of $3 \mathrm{~h} 15 \mathrm{~min} 55 \mathrm{~s}$.

In summary, we demonstrated a smart thermostat prototype generally capable of supporting isothermal NAAT protocols within $35-65^{\circ} \mathrm{C}$ range in $2 \mathrm{~cm} \times 3 \mathrm{~cm} \mathrm{LoC} \mathrm{cartridges} \mathrm{at} 20-30{ }^{\circ} \mathrm{C}$ ambient temperatures. The proposed thermostat offers a user-friendly dual user interface (local and remote via Bluetooth), over $3 \mathrm{~h}$ battery life on a single charge, compact size $(12 \mathrm{~cm} \times 8 \mathrm{~cm} \times 5 \mathrm{~cm})$ and low cost ( 50-100 EUR). The key advantages of this prototype are (1) complete portability, (2) remote control and monitoring, (3) good balance between cost and performance. Portability (1) makes field applications possible (e.g., in agriculture, on a farm) by running from the internal battery. Furthermore, the thermostat can be remotely monitored and controlled (2), allowing unattended operation in the field, or controlling several instruments at once. The Bluetooth interface also allows integration and networking with additional instruments (e.g., pumps, sensors, etc.) and automated control from a dedicated computer without any wires that could make field deployment difficult. Finally, the low cost (3) ensures a wider exploitation of isothermal LoC NAAT technology as well as easy integration into low-cost field analysis equipment. As part of a longer plan to deliver low-cost, user-friendly electronics for LoC, the demonstrated thermostat prototype will facilitate large-scale application of isothermal LoC NAAT in research and potentially education. 
Author Contributions: Conceptualization, T.P. and H.S.; methodology, T.P.; software, H.S.; validation, H.S; formal analysis, T.P. and H.S.; investigation, H.S.; resources, T.R.; writing—original draft preparation, T.P.; writing-review and editing, T.R. and A.K.; visualization, T.P. and H.S.; supervision, T.R.; project administration, T.R.; funding acquisition, T.R. and A.K.

Funding: This research was funded by the Estonian Research Council under project IUT19-11, PUT1435 and TAR16013 Center of Excellence 'EXCITE IT', the European Commission under Horizon 2020 ERA-chair Grant 'Cognitive Electronics COEL'-H2020-WIDESPREAD-2014-2 (Agreement number: 668995; project TalTech code VFP15051).

Acknowledgments: The authors wish to express their gratitude to the Estonian Research Council and the European Commission for their support under projects detailed under Funding.

Conflicts of Interest: The authors declare no conflict of interest. The funders had no role in the design of the study; in the collection, analyses, or interpretation of data; in the writing of the manuscript, or in the decision to publish the results.

\section{References}

1. Erlich, H.A. Polymerase chain reaction. J. Clin. Immunol. 1989, 9, 437-447. [CrossRef] [PubMed]

2. Garibyan, L.; Avashia, N. Polymerase Chain Reaction. J. Investig. Dermatol. 2013, 133, 1-4. [CrossRef] [PubMed]

3. Ahn, C.H.; Choi, J.-W.; Beaucage, G.; Nevin, J.; Lee, J.-B.; Puntambekar, A.; Lee, R.J.Y. Disposable Smart Lab on a Chip for Point-of-Care Clinical Diagnostics. Proc. IEEE 2004, 92, 154-173. [CrossRef]

4. Pais, A.; Banerjee, A.; Klotzkin, D.; Papautsky, I. High-sensitivity, disposable lab-on-a-chip with thin-film organic electronics for fluorescence detection. Lab Chip 2008, 8, 794-800. [CrossRef] [PubMed]

5. Srinivasan, V.; Pamula, V.K.; Fair, R.B. An integrated digital microfluidic lab-on-a-chip for clinical diagnostics on human physiological fluidsThe Science and Application of Droplets in Microfluidic Devices.Electronic supplementary information (ESI) available: Five video clips showing: High-spe. Lab Chip 2004, 4, 310. [CrossRef] [PubMed]

6. Mark, D.; Haeberle, S.; Roth, G.; Von Stetten, F.; Zengerle, R. Microfluidic Lab-on-a-Chip Platforms: Requirements, Characteristics and Applications. In Microfluidics Based Microsystems; Springer: Dordrecht, The Netherlands, 2010; pp. 305-376.

7. Mori, Y.; Notomi, T. Loop-mediated isothermal amplification (LAMP): A rapid, accurate, and cost-effective diagnostic method for infectious diseases. J. Infect. Chemother. 2009, 15, 62-69. [CrossRef] [PubMed]

8. Notomi, T. Loop-mediated isothermal amplification of DNA. Nucleic Acids Res. 2000, 28, e63. [CrossRef] [PubMed]

9. Craw, P.; Balachandran, W. Isothermal nucleic acid amplification technologies for point-of-care diagnostics: A critical review. Lab Chip 2012, 12, 2469. [CrossRef]

10. Asiello, P.J.; Baeumner, A.J. Miniaturized isothermal nucleic acid amplification, a review. Lab Chip 2011, 11, 1420. [CrossRef]

11. Velve Casquillas, G.; Fu, C.; Le Berre, M.; Cramer, J.; Meance, S.; Plecis, A.; Baigl, D.; Greffet, J.J.; Chen, Y.; Piel, M.; et al. Fast microfluidic temperature control for live high resolution cell imaging. Lab Chip 2011, 11, 484-489. [CrossRef]

12. Velve-Casquillas, G.; Costa, J.; Carlier-Grynkorn, F.; Mayeux, A.; Tran, P.T. A Fast Microfluidic Temperature Control Device for Studying Microtubule Dynamics in Fission Yeast. In Methods in Cell Biology; Elsevier: Amsterdam, The Netherlands, 2010; Volume 97, pp. 185-201. ISBN 978-0-12-381349-7.

13. Maltezos, G.; Johnston, M.; Taganov, K.; Srichantaratsamee, C.; Gorman, J.; Baltimore, D.; Chantratita, W.; Scherer, A. Exploring the limits of ultrafast polymerase chain reaction using liquid for thermal heat exchange: A proof of principle. Appl. Phys. Lett. 2010, 97, 264101. [CrossRef] [PubMed]

14. Schumacher, S.; Nestler, J.; Otto, T.; Wegener, M.; Ehrentreich-Förster, E.; Michel, D.; Wunderlich, K.; Palzer, S.; Sohn, K.; Weber, A.; et al. Highly-integrated lab-on-chip system for point-of-care multiparameter analysis. Lab Chip 2012, 12, 464-473. [CrossRef] [PubMed]

15. Scorzoni, A.; Tavernelli, M.; Placidi, P.; Zampolli, S. Thermal modeling and characterization of a thin-film heater on glass substrate for lab-on-chip applications. IEEE Trans. Instrum. Meas. 2015, 64, 1215-1222. [CrossRef] 
16. Moschou, D.; Vourdas, N.; Kokkoris, G.; Papadakis, G.; Parthenios, J.; Chatzandroulis, S.; Tserepi, A. All-plastic, low-power, disposable, continuous-flow PCR chip with integrated microheaters for rapid DNA amplification. Sens. Actuators B Chem. 2014, 199, 470-478. [CrossRef]

17. Jiao, Z.; Huang, X.; Nguyen, N.T.; Abgrall, P. Thermocapillary actuation of droplet in a planar microchannel. Microfluid. Nanofluid. 2008, 5, 205-214. [CrossRef]

18. Lederer, T.; Hilber, W.; Jakoby, B. Fast thermo-pneumatic actuation of a thin PDMS membrane using a micro Peltier-element for microfluidic applications. Elektrotech. Inf. 2009, 126, 70-74. [CrossRef]

19. Bar-Cohen, A.; Wang, P. On-chip thermal management and hot-spot remediation. In Nano-Bio-Electronic, Photonic and MEMS Packaging; Springer: Boston, MA, USA, 2010; pp. 349-429. ISBN 9781441900395.

20. Maltezos, G.; Johnston, M.; Scherer, A. Thermal management in microfluidics using micro-Peltier junctions. Appl. Phys. Lett. 2005, 87, 1-3. [CrossRef]

21. Pardy, T.; Rang, T.; Tulp, I. Thermal analysis of a disposable, instrument-free DNA amplification lab-on-a-chip platform. Sensors 2018, 18, 1812. [CrossRef]

22. Pardy, T.; Tulp, I.; Kremer, C.; Rang, T.; Stewart, R. Integrated self-regulating resistive heating for isothermal nucleic acid amplification tests (NAAT) in Lab-on-a-Chip (LoC) devices. PLoS ONE 2017, 12, e0189968. [CrossRef]

23. Wyzkiewicz, I.; Grabowska, I.; Chudy, M.; Brzozka, Z.; Jakubowska, M.; Wisniewski, T.; Dybko, A. Self-regulating heater for microfluidic reactors. Sens. Actuators B Chem. 2006, 114, 893-896. [CrossRef]

24. Khazai, B.; Nichols, G.M. Self-Regulating Polymer Composite Heater. U.S. Patent 5,902,518, 11 May 1999.

25. Oakes, J.A.; Sandberg, C.L. Some Aspects of a Self-Limiting Resistive Electric Heating Element. IEEE Trans. Ind. Appl. 1973, IA-9, 462-466. [CrossRef]

26. Almassian, D.R.; Cockrell, L.M.; Nelson, W.M. Portable nucleic acid thermocyclers. Chem. Soc. Rev. 2013, 42, 8769-8798. [CrossRef] [PubMed]

27. Buser, J.; Domingo-villegas, G.J.; Lewis, J.; Labarre, P.D.; Hans, B. Chemical Temperature Control. U.S. Patent 8,431,387, 30 April 2009.

28. Buser, J.R.; Diesburg, S.; Singleton, J.; Guelig, D.; Bishop, J.D.; Zentner, C.; Burton, R.; Labarre, P.; Yager, P.; Weigl, B.H. Precision chemical heating for diagnostic devices. Lab Chip 2015, 15, 4423-4432. [CrossRef] [PubMed]

29. Weigl, B.; Domingo, G.; LaBarre, P.; Gerlach, J. Towards non- and minimally instrumented, microfluidics-based diagnostic devices. Lab Chip 2008, 8, 1999-2014. [CrossRef] [PubMed]

30. Singleton, J.; Zentner, C.; Buser, J.; Yager, P.; LaBarre, P.; Weigl, B.H. Instrument-free exothermic heating with phase change temperature control for paper microfluidic devices. In Proceedings of the Microfluidics, BioMEMS, and Medical Microsystems XI, San Francisco, CA, USA, 3-5 February 2013; Volume 8615, p. $86150 R$.

31. Niemz, A.; Ferguson, T.M.; Boyle, D.S. Point-of-care nucleic acid testing for infectious diseases. Trends Biotechnol. 2011, 29, 240-250. [CrossRef] [PubMed]

32. Kumar, S.; Cartas-Ayala, M.A.; Thorsen, T. Thermal modeling and design analysis of a continuous flow microfluidic chip. Int. J. Therm. Sci. 2013, 67, 72-86. [CrossRef]

33. Chien, L.-J.; Wang, J.-H.; Hsieh, T.-M.; Chen, P.-H.; Chen, P.-J.; Lee, D.-S.; Luo, C.-H.; Lee, G.-B. A micro circulating PCR chip using a suction-type membrane for fluidic transport. Biomed. Microdevices 2008, 11, 359-367. [CrossRef]

34. Lee, D.S.; Park, S.H.; Yang, H.; Chung, K.H.; Yoon, T.H.; Kim, S.J.; Kim, K.; Kim, Y.T. Bulk-micromachined submicroliter-volume PCR chip with very rapid thermal response and low power consumption. Lab Chip 2004, 4, 401-407. [CrossRef]

35. Lee, N.Y. Recent Progress in Lab-on-a-Chip Technology and Its Potential Application to Clinical Diagnoses. Int. Neurourol. J. 2013, 17, 2. [CrossRef]

36. Dolomite. Meros Temperature Control Unit|Dolomite Microfluidics. Available online: https://www.dolomitemicrofluidics.com/product/meros-temperature-control-unit/ (accessed on 8 May 2019).

37. Lutz, S.; Weber, P.; Focke, M.; Faltin, B.; Hoffmann, J.; Müller, C.; Mark, D.; Roth, G.; Munday, P.; Armes, N.; et al. Microfluidic lab-on-a-foil for nucleic acid analysis based on isothermal recombinase polymerase amplification (RPA). Lab Chip 2010, 10, 887-893. [CrossRef]

38. Stacey, K. Arduino PCR (Thermal Cycler) for under $\$ 85$. Available online: https://www.instructables.com/id/ Arduino-PCR-thermal-cycler-for-under-85/ (accessed on 21 May 2019). 
39. Myers, F.B.; Henrikson, R.H.; Bone, J.; Lee, L.P. A Handheld Point-of-Care Genomic Diagnostic System. PLOS ONE 2013, 8, e70266. [CrossRef]

40. Lu, H.-W.; Roskos, K.; Hickerson, A.I.; Carey, T.; Niemz, A. System for portable nucleic acid testing in low resource settings. In Microfluidics, BioMEMS, and Medical Microsystems XI; Becker, H., Gray, B.L., Eds.; International Society for Optics and Photonics: Bellingham, WA, USA, 2013; p. 86150I.

41. Craw, P.; Mackay, R.; Naveenathayalan, A.; Hudson, C.; Branavan, M.; Sadiq, S.; Balachandran, W.; Craw, P.; Mackay, R.E.; Naveenathayalan, A.; et al. A Simple, Low-Cost Platform for Real-Time Isothermal Nucleic Acid Amplification. Sensors 2015, 15, 23418-23430. [CrossRef] [PubMed]

42. MoBiTec. MoBiTec: Theater Slim PCR Cycler from Coyote Bioscience. Available online: https://www.mobitec. com/cms/products/bio/10_lab_suppl/theater_slim_PCR_cycler.html (accessed on 21 May 2019).

43. MiniPCR. miniPCR ${ }^{\mathrm{TM}}$ mini8 Thermal Cycler-miniPCR. Available online: https://www.minipcr.com/product/ minipcr-mini8-thermal-cycler/ (accessed on 21 May 2019).

44. Sigma-Aldrich. TC-9639 Thermal Cycler. Available online: https://www.sigmaaldrich.com/catalog/substance/ tc9639thermalcycler1234598765?lang=en\&region=EE (accessed on 21 May 2019).

45. Sigma-Aldrich. IKA ${ }^{\circledR}$ C-MAG HS digital IKAMAG ${ }^{\mathrm{TM}}$ Hot Plate Magnetic Stirrers. Available online: https: //www.sigmaaldrich.com/catalog/product/aldrich/z767700?lang=en\&region=EE (accessed on 21 May 2019).

46. Pardy, T.; Rang, T.; Tulp, I. Finite Element Modelling for the Optimization of Microheating in Disposable Molecular Diagnostics. Int. J. Comput. Methods Exp. Meas. 2017, 5, 13-22. [CrossRef]

47. Pardy, T.; Rang, T.; Tulp, I. Modelling and experimental characterisation of self-regulating resistive heating elements for disposable medical diagnostics devices. WIT Trans. Eng. Sci. 2015, 90, 263-271.

48. Pardy, T.; Rang, T.; Tulp, I. Finite element modelling of the resistive heating of disposable molecular diagnostics devices. WIT Trans. Model. Simul. 2015, 59, 381-391.

49. Pardy, T.; Rang, T.; Tulp, I. Modelling and experimental characterisation of thermoelectric heating for molecular diagnostics devices. In Proceedings of the 15th Biennial Baltic Electronics Conference, Tallinn, Estonia, 3-5 October 2016; Volume 2016-Novem.

50. Pardy, T.; Rang, T.; Tulp, I. Development of temperature control solutions for non-instrumented nucleic acid amplification tests (NINAAT). Micromachines 2017, 8, 180. [CrossRef]

51. Pardy, T.; Rang, T.; Kremer, C.; Tulp, I. Instrument-free Lab-on-a-Chip DNA amplification test for pathogen detection. In Proceedings of the 16th Biennial Baltic Electronics Conference (BEC), Tallinn, Estonia, 8-10 October 2018; pp. 1-4.

52. Tamas, P. Microheating Solution for Molecular Diagnostics Devices. Ph.D. Thesis, Tallinn University of Technology, Tallinn, Estonia, 2018.

53. Systems, E. ESP32 Series (Datasheet). Available online: https://www.espressif.com/sites/default/files/ documentation/esp32_datasheet_en.pdf (accessed on 26 April 2019).

54. Github. Arduino Core for the ESP32. Available online: https://github.com/espressif/arduino-esp32 (accessed on 26 April 2019).

55. Espressif. BLE Max Transmission Range-ESP32 Forum. Available online: https://www.esp32.com/viewtopic. php?t=6959 (accessed on 11 June 2019).

56. MIT. MIT App Inventor|Explore MIT App Inventor. Available online: http://appinventor.mit.edu/explore/\# (accessed on 8 May 2019).

57. Friess, H.; Haussener, S.; Steinfeld, A.; Petrasch, J. Tetrahedral mesh generation based on space indicator functions. Int. J. Numer. Methods Eng. 2013, 93, 1040-1056. [CrossRef]

58. He, F. Standard PCR Protocol. Available online: https://www.sigmaaldrich.com/technical-documents/ protocols/biology/standard-pcr.html (accessed on 23 April 2019).

(C) 2019 by the authors. Licensee MDPI, Basel, Switzerland. This article is an open access article distributed under the terms and conditions of the Creative Commons Attribution (CC BY) license (http://creativecommons.org/licenses/by/4.0/). 